\title{
Historia y escatología en Manuel Lacunza. La temporalidad a través del milenarismo lacunziano
}

\section{INTRODUCCIÓN}

La obra de Manuel Lacunza (1) (1731-1801) se puede considerar un sistema, ya que cuenta con un conjunto de concepciones, que unidas forman un todo coherente en torno a un principio central, a saber, la esperanza mesiánica y milenarista de un reino terrestre de Jesucristo antes del fin definitivo de la historia y del tránsito hacia la eternidad. Por ello, su obra contiene una determinada visión de la historia actual, una visión de la Parusía o Segunda Venida de Cristo, un concepto peculiar del reino mesiánico-terrestre del Señor y sus santos, una visión de la Iglesia actual y futura y, en fin, una idea de la Bienaventuranza Eterna. A estos temas me he referido en otras oportunidades (2). A seguir nos preguntamos exclusivamente por la

(1) Para conocer la biografía y bibliografía de Manuel Lacunza, y para contextualizar la circulación de su obra se pueden consultar las siguientes fuentes: Francisco Mateos, el P. Manuel Lacunza y el Milenarismo, Rev. Chilena de Historia y Geografía, 115 (1950), pp. 134-161; Pedro P. Figueroa, Diccionario Biográfico de Chile, Santiago, 1987, p. 147-148; L. F. Prieto del Río, Diccionario Biográfico del Clero secular de Chile, Santiago, 1922, p. 354; José Toribio Medina, Noticias biobibliográficas de los jesuitas expulsos de América en 1767, Santiago, 1914, p. 183-184; José I. V. Eyzaguirre Portales, Historia eclesiástica, política y literaria de Chile, Valparaíso, 1850, II, p. 213, 313-314; Miguel Luis Amunátegui Reyes, Compendio de la Historia política y eclesiástica de Chile, 13 ed., Santiago, 1896, p. 148; Diego Barros Arana, Historia General de Chile, Santiago, 1886, T. VI, p. 276-277, 293, T. VII, p. 569-573, 584; Alfred-Félix Vaucher, Une celebrité oubliée, Le P. Manuel Lacunza y Díaz (1731-1801), Fides, Collonges-sous-Salève, Haute Savoie, 1941, p. 27-34 (2 ${ }^{\mathrm{a}}$ Ed. 1968); Walter Hanisch, El Padre Manuel Lacunza (1731-1801), su hogar, su vida y la censura española, Rev. Historia 8 (1969), p. 157-232. Para la situación histórica general ver: Paul Christophe, L'Eglise dans l'histoire des hommes, T. II, du XV siècle à nos jours, Limoges, Droguet e Ardant, 1983, p. 260-263. Giacomo Martina, La Iglesia, de Lutero a nuestros días. II, Epoca del Absolutismo, Cristiandad, Madrid, 1974, pp. 271-287; Jean Guennou, Las misiones católicas, en H. Ch. Puech, Historia de las religiones, Vol. 8, Las religiones constituidas en Occidente y sus contracorrientes, II, 2 ed., México, Siglo XXI, 1981, p. 147 y ss.

(2) Cf. F. Parra, El reino que ha de venir. Historia y esperanza en la obra de Manuel Lacunza, Anales de la Facultad de Teología, PUCCh, XLIV, c. 2, Santiago de Chile, 1993, 219 pp.; Id., Historia y esperanza en la obra de Manuel Lacunza, Teología y Vida, Vol. XXXV (1994), pp. 135-152; Id., El fin del mundo según Lacunza, Teología y Vida, Vol. XLI (2000), pp. 64-80; Id., El regreso de Jesucristo; Crítica y actualidad de Lacunza, Artes y Letras, El Mercurio, 17 de junio de 2001, E12 y E-13; Manuel Lacunza: su obra y su visión de la historia. $1^{a}$ parte, La Revista Católica, 
visión del tiempo implícita y explícita en La Venida del Mesías en Gloria y Majestad, libro que nuestro autor concluyó en 1790.

$\mathrm{Si}$ la historia es un proceso que se desarrolla en el tiempo, un supuesto fundamental de toda teología de la historia es, ciertamente, la inteligencia del tiempo. De ahí que el significado que se le otorga a la historia esté directamente vinculado con la comprensión del tiempo. Para indagar la visión del tiempo en la obra de Lacunza, el artículo desarrolla los siguientes puntos: I. Tiempo, tiempos, "eones" y eternidad; II. Los dos tiempos (venidas) del Mesías; III. Tensión temporal y acción en el sistema de Lacunza; IV. Parusía y tiempo en el debate contemporáneo.

\section{TIEMPO, TIEMPOS, "EONES” Y ETERNIDAD}

Lacunza comprende la temporalidad haciendo suya la perspectiva judeocristiana que encuentra en su atenta lectura de la Sagrada Escritura. Cabe hacer notar que, al igual que en otros aspectos, el autor no se plantea explícitamente la pregunta por el tiempo y, por tanto, tampoco se encuentra una respuesta directa a nuestro asunto. Se trata de una pregunta que nosotros le estamos haciendo desde nuestras inquietudes y desde nuestro contexto histórico (y temporal). En todo caso, es una preocupación que atraviesa toda la obra lacunziana. Uno de sus objetivos, si no el mayor, está definido como la necesidad de encontrar un tiempo para el cumplimiento mesiánico.

Uniendo elementos proféticos y apocalípticos, Lacunza contempla la historia desde la eternidad, desde una perspectiva de plenitud que supera todas las contradicciones del tiempo actual. Esta eternidad no es otra que la eternidad de Dios que se manifiesta como Señor y conductor del tiempo y que puede revelarse constantemente en la historia humana. En principio, el tiempo es el ámbito donde ocurre y se expresa la permanente eternidad de Dios.

Cabe recordar que la palabra "eternidad" no denota en el pensamiento bíblico (hebreo) "el sentido de prolongación infinita, vacía, abstracta y lineal del tiempo que nosotros le damos, sino que equivale al 'tiempo' en toda su extensión infinita. Por consiguiente, el término también puede significar 'el caminar del mundo' (eón), o, sencillamente, 'el mundo' mismo en cuanto totalidad de tiempo y de espacio. Para el hebreo, 'el tiempo' no es una noción formal y vacía, un concepto o categoría en el sentido kantiano, sino que es inseparable de la totalidad de su contenido. 'El tiempo' es todo lo que existe y sucede en el tiempo. Es la suma del contenido de los años" (3).

2001, octubre-diciembre, $N^{\circ} 1.132$, pp. 326-337; Id., Manuel Lacunza: su obra y su visión de la historia, $2^{a}$ parte, La Revista Católica, 2002, enero-marzo, № 1.133, pp. 29-38.

(3) S. Mowinckel, El que ha de venir. Mesianismo y mesías, Ed. Fax, Madrid, 1975, pp. 116-117, el destacado es mío. Más adelante Mowinckel añade: "Uno de los nombres que se aplican al regio infante (Mesías) en Is 9 es 'abi ad, traducido generalmente por 'Padre sempiterno' (Padre siempre). Esto recuerda, naturalmente, el antiguo título cananeo del dios supremo 'El', 'Padre de los Años' y el título egipcio del dios creador Ptah, 'Señor de los Años', 'Señor de la Eternidad'. En todas estas expresiones yace, indudablemente, la misma idea. El hecho de que 'perpetuidad' sea aquí símbolo de 'años' demuestra que no se trata de nuestra concepción de 'eternidad', abstracta e independiente del tiempo, sino que 'ad, al igual que el vocablo usual olam, significa aquí 'el tiempo' con todo su contenido: todo lo que en él sucede desde el principio hasta el insondable futuro. El Dios creador es Señor y autor de todo lo que ocurre durante este tiempo sin fin" (Mowinckel, o. c., p. 199). 
En resumen, no se trata de una concepción de 'eternidad' independiente del tiempo, sino que se refiere al tiempo con todo su contenido: todo lo que en él sucede desde el principio hasta el insondable futuro. El Dios creador es Señor y autor de todo lo que ocurre durante este tiempo sin fin.

Dios mismo -Padre siempre- es la "duración" por excelencia, exenta de sucesión, sin principio ni fin, permanente presencia, que posee el tiempo en plenitud. Sin embargo, y sin negar lo anterior, los cristianos creemos que Dios eterno no solo ha creado la historia, sino que constantemente manifiesta su soberanía sobre el tiempo y la historia. Tanto es así que creemos que el Hombre-Dios asume la temporalidad y de ese modo entra la eternidad en el tiempo e inaugura el último tiempo que precede el reino verdaderamente eterno. Priorizando el polo de la Segunda Venida, Lacunza se distancia de esta última idea y con ello de la ortodoxia católica vigente. En su discurso, la Parusía o Segunda Venida también significa la entrada de la eternidad en el tiempo, pero no suprime ni el mundo ni el tiempo, por tanto, tampoco suprime la historia. Y después de la Segunda Venida (en gloria y majestad) se inicia un tiempo indeterminado de dicha, paz y justicia universal que precede y se distingue claramente de la vida eterna. Con todo, el tiempo no acaba con la Venida que estamos esperando, muy por el contrario, seguirá siendo el lugar donde se manifiesta la soberanía de Dios de un modo más pleno mientras dure la era mesiánica (el milenio).

Subyace en el planteamiento lacunziano la tesis apocalíptica según la cual el tiempo se divide e, eones (siglos). Contrapone dos épocas cualitativamente diversas: el eón presente y el eón futuro. No obstante, ambos siguen siendo eones y como tales sometidos a un dinamismo temporal. Explica Lacunza que "siglo se llama no solamente la revolución de cien años, sino también, y con más propiedad, todo el aparato externo de nuestro mundo, o de nuestro globo, su fausto, su lujo, su engaño, su vanidad, su mentira, su pecado. En suma, se llama siglo el día actual de los hombres, de su potestad, de su dominación, el de su virtud, de su juicio, de su gobierno, etc., a distinción del día del Señor. Yo hallo muchas veces en las Escrituras, principalmente en los evangelios, estas palabras: consumación del siglo... En este sentido, pues, en que hablan otras Escrituras, dice Daniel, que la desolación actual de Jerusalén, que empezó después de la muerte del Mesías, deberá perseverar hasta la consumación, y fin: es decir, hasta que se concluya, y llegue a su fin el día presente, y empiece a amanecer el día del Señor; hasta que venga el Mesías en gloria y majestad, y con su venida tenga principio el día de su virtud en los esplendores de los Santos" (4).

Es sabido que "las palabras de Oseas, Amós o Isaías tan solo conocen un mundo (un siglo), que es también el escenario de los grandes sucesos del final de los tiempos, y su escatología tiene un carácter nacional... Por el contrario, en la apocalíptica se propone la doctrina de los dos eones, que se siguen uno a otro y se encuentran en una relación antitética: este mundo y el mundo futuro, el imperio de la tinieblas y el de la luz. La antítesis nacional entre Israel y los paganos se ensan-

(4) M. Lacunza, La Venida del Mesías en Gloria y Majestad, (4 Tomos), Ed. C. Wood, Londres, 1816, III, pp. 414-415; Cf. III, 394. En adelante citaremos el $\mathrm{N}^{\circ}$ del tomo respectivo y las páginas correspondientes. 
cha hasta una antítesis cósmica. Los ámbitos respectivos de la santidad y del pecado, de lo puro y de lo impuro, de la vida y de la muerte, de la luz y de las tinieblas, Dios y los poderes que le son hostiles, se oponen" (5).

Es claro que el proyecto de nuestro jesuita se afirma en la espera de la irrupción de una dimensión temporal nueva en la historia del mundo. Se subraya la ruptura, la salvación que viene con el nuevo eón no es consecuencia directa de la historia que la precede; no es perceptible un tránsito entre el siglo presente y la salvación que viene. La perfección que irrumpe no es resultado de ningún proceso premilenial intramundano. Por lo mismo no hay lugar para un progreso de la historia, del siglo actual, hacia la salvación que trae el siglo futuro.

La esperanza milenarista de raíces proféticas y apocalípticas formulada por nuestro jesuita mira, en consecuencia, al cambio de los tiempos, con la confianza puesta en el poder de Dios quien reemplazará este eón de desgracia por un eón de justicia y felicidad. Es posible, sobre todo desde nuestra perspectiva moderna, advertir un cierto dualismo en esta visión de los dos eones. Sin embargo, no se puede deducir, sin más, la presencia de un dualismo radical. En efecto, no hay una ruptura de la historia en términos absolutos. El poder de Dios transforma la historia y el cosmos, pero no se destruye todo rastro de continuidad: esta misma tierra recupera condiciones paradisíacas y permanece un resto de las naciones. El énfasis se coloca en la perfección de dimensiones ya existentes: "conque los nuevos cielos, y nиеva tierra, o el mundo nuevo que esperamos después del presente, debe ser sin comparación mejor que el presente, y esto no solamente en lo moral, sino también en lo físico y material. En lo moral, porque en él habitará la justicia (las cuales palabras generales no se pueden decir con verdad ni del mundo presente ni mucho menos del antiguo). También en lo físico y material, porque el mundo nuevo que esperamos, lo esperamos según las promesas de Dios; y estas promesas que solo constan del cap. 65 de Isaías, hablan expresa y claramente de una bondad moral, y también física y material" (6). En suma, en palabras de Lacunza, esperamos una gran mudanza "de nuestro mundo presente de mal en bien" (7).

En realidad si cabe la caracterización de dualismo se podría hablar de un dualismo ético y temporal, donde se destaca la lucha entre el bien y el mal que constituye la trama principal de la historia humana. El todo sigue siendo creación de Dios; los dos eones con sus respectivas fuerzas y tendencias forman parte de una única creación.

Al irrumpir el final de este tiempo, de este eón, esto es, al surgir un tiempo radicalmente nuevo, pareciera que la eternidad se aproxima y la perfección física y moral sugiere la presencia de condiciones paradisíacas. Sin embargo, la tierra, la historia y la humanidad continúan sometidas al tiempo y se distinguen de la eternidad. La nueva vida que emerge con el nuevo eón no es como lo sería desde perspectivas griegas o gnósticas una vida puramente espiritual en contraposición a la vida corporal. Se trata más bien de un perfeccionamiento de la existencia física, corporal,

(5) G. Scholem, Le messianisme juif. Essais sur la spiritualité du judaïsme, Calmann-Lévy, Paris, 1974, pp. 29-30. Cf., N. Cohn, El cosmos, el caos y el mundo venidero, Ed. Crítica, Barcelona, 1995, pp. 145-237.

(6) Lacunza, o. c., IV, pp. 81, el destacado en cursiva es mío.

(7) Ibíd., el destacado es mío. 
en esta tierra, una restauración de la perfección existente en los momentos originales, una transfiguración de la vida corporal, y no la abolición de la misma.

Puntualiza Lacunza que con el aparecer de una nueva tierra y un nuevo cielo será "todo tan bueno, a lo menos como lo fue en su estado primitivo: digo a lo menos, porque me parece, no solo posible, sino sumamente verosímil, que por respeto y honor de una persona de infinita dignidad cual es un Hombre Dios, por quien, y para quien, como dice San Pablo... fueron creadas todas las cosas, se renueve, y se mejore todo en nuestro orbe, dándosele a este, aun en lo natural... un nuevo y sublime grado de perfección" (8). En otro lugar, el autor explica que en el siglo venturo los seres humanos serán tan viadores como lo son ahora y estarán dotados de su libre albedrío, que entonces andarán por fe y no por visión, al igual que ahora; por consiguiente, los hombres del siglo que viene serán libres, capaces de bien o de mal, de merecer o desmerecer (9).

A pesar de su perfección, el milenio sigue siendo penúltimo. Y si ya el eón futuro, el milenio, conocerá la perfección, Lacunza se pregunta “¿qué pensáis que será después de la resurrección universal, cuando acabada toda generación y corrupción, cuando concluido y consumado perfectamente todo el gran misterio de Dios con los hombres, sea esta misma tierra sublimada a la dignidad altísima, y eterna, de... centro de unidad de todo lo creado, o del inmenso reino de los cielos?, ¿no es infinitamente verosímil, que se le añadan, entonces, mil o un millón de grados de perfección física y moral?" (10). En todo caso, para Lacunza es imposible imaginar un digno concepto de lo que será la felicidad eterna en la contemplación de la naturaleza transfigurada y la comunión eterna con Dios que experimentarán los justos resucitados "pues como está escrito en Isaías (Is 64, 3): ojo no vio ni oreja oyó, como lo repite S. Pablo (1 Cor 2, 9), ni en corazón de hombre subió, lo que preparó Dios para aquellos que le aman" (11). En resumen, el universo renovado, acabada toda generación y corrupción, participará de la plenitud eterna y tras la resurrección universal, los bienaventurados gozarán juntos eternamente de la contemplación del mundo bellamente transfigurado y de la comunión con Dios Padre. Siempre se trata de una transformación de la materia de mal en bien, o de bien en mejor. La idea de una aniquilación del mundo queda claramente excluida del sistema de Lacunza.

Así como hubo continuidad y ruptura entre el eón presente y el eón futuro, así también la habrá entre el eón futuro y la vida eterna. Sin duda, una continuidad diferente: el espacio permanece, aunque se transfigura de un modo indescriptible para convertirse en residencia final de los bienaventurados. Con todo, parece acertado deducir que, más allá del modelo representativo utilizado, Lacunza admite que el tiempo pueda entrar en la eternidad y esta en aquel. En su teología tiempo y eternidad no se oponen ni se excluyen, sino que están íntimamente implicados. Para nuestro autor, el tiempo es una realidad abierta. El tiempo del eón presente está abierto al nuevo tiempo que adviene con la llegada del Mesías y ambos eones están

\footnotetext{
(8) Lacunza, o. c., IV, pp. 92-93.

(9) Ibíd., IV, pp. 66, 337-338, 341.

(10) Ibíd., IV, pp. 428-429.

(11) Ibíd., IV., p. 430.
} 
abiertos, a su vez, a la eternidad que no deja nunca de comunicarse con la historia. No obstante su imperfección, nuestra época actual es un eón de la vida eterna, así como el futuro también lo es. Todas estas dimensiones están íntimamente conectadas por un surco de continuidad donde nunca están ausentes elementos espaciales, terrenos o humanos transfigurados. Los eones son, en suma, períodos interiores de la eternidad. "Esta concepción pone de manifiesto el antiguo realismo israelita con su sana oposición a lo puramente espiritual. Lo transcendental y supraterrestre nunca deviene lo meramente espiritual, abstracto, invisible, intangible y vacío. Lo 'totalmente distinto' de la religión bíblica jamás se convierte en aquello que solo se puede expresar mediante negaciones" (12).

Queda establecido que no se trata en estos planteamientos de una eternidad via negationis, una eternidad que resulta de la negación de todo cambio y novedad. En este contexto, la eternidad no se postula como negación del tiempo sino como "afirmación de él en todos los tiempos; en otros términos, 'eternidad' significa aquí totalización del tiempo" (13). Por lo mismo O. Cullmann "pudo precisar que la eternidad -que debe ser concebida como un atributo de Dios- es un tiempo infinito; en términos más claros, lo que se llama 'tiempo' no es otra cosa que una fracción, limitada por Dios, de la duración ilimitada del tiempo de Dios (14). (...) Por lo demás la exégesis neotestamentaria se encuentra... en condiciones de afirmar que la palabra aiôn (eón) expresa, a la vez, la eternidad, prevista como tiempo ilimitado, y el tiempo histórico, considerado como tiempo limitado. Para Dios, como para el hombre, en razón de la unicidad de la historia de la salvación, el tiempo y la eternidad van unidos por una relación lineal cada vez más estrecha. Naturalmente que la eternidad no es el tiempo y que la distinción debe mantenerse, pero no como una oposición. (...) La diferencia entre el tiempo y la eternidad se sitúa, según parece, en la confrontación entre un tiempo determinado y un tiempo sin límite" (15).

En este sentido, y a la luz de estos análisis, se comprende mejor que la historia constituye, para Lacunza, una profunda interacción entre la eternidad y el tiempo, el advenimiento constante de aquella en este. En el sistema de Lacunza subyace una aspiración que afecta a ambos eones: la de llegar a un tiempo íntegro, sin desgarramientos, que pueda asumir positivamente todo pasado. De este modo la resurrección se constituye en el momento culminante en que el tiempo, los eones diversos, se abren definitivamente a lo eterno.

\section{LOS DOS TIEMPOS (VENIDAS) DEL MESÍAS}

El primer advenimiento de Jesucristo marcó una línea divisoria entre judíos y cristianos. Desde entonces el cristiano cuenta y experimenta su tiempo desde un acontecimiento central que ocurrió - de acuerdo a la conciencia cristiana- cuando el tiempo se había cumplido (Mc 1, 14-15): Cristo viene a ser este acontecimiento

(12) Mowinckel, o. c., p. 299

(13) W. Rehfeld, Tempo e religiao, Ed. Perspectiva, São Paulo, 1988, p 165; cf., pp. 71-101.

(14) Cf., O. Cullmann, Cristo y el tiempo, Barcelona, 1968, p. 44.

(15) G. Páttaro, La concepción cristiana del tiempo, en: P. Ricoeur, dir., Las culturas y el tiempo, Sígueme, Salamanca, 1979, pp. 198-199. 
central que explica y da sentido a toda historia y con él ya comienzan los tiempos escatológicos y solo cabe aguardar la consumación, que normalmente implica el fin de la historia y el inicio de la vida eterna. Cristo es el centro, su muerte y resurrección constituyen la clave para comprender las etapas de la historia del mundo. Los últimos tiempos ya se han iniciado y, en consecuencia, la era mesiánica ya habita la historia.

Para los judíos, en cambio, el acontecimiento central se encuentra situado aún en el futuro y es por ello que continúan esperando el momento mesiánico, o la venida del Mesías, único capaz de abrir la era mesiánica. El Mesías divide la historia en un eón presente y otro futuro donde tiene lugar el cumplimiento. Como se sabe, la idea mesiánica de origen judío rompe con el paradigma cíclico de la humanidad; la historia no es el eterno retorno de lo mismo y no se mueve en círculos; la historia se mueve hacia una meta futura. "Es cierto también que las predicciones de los profetas no nos entregan concepciones de mesianismo muy claras. Encontramos temas múltiples: una fuerte corriente utópica orientada hacia la visión de una humanidad mejor al final de los tiempos que siempre confluye con la corriente restauradora que espera el restablecimiento de un reino davídico ideal" (16).

Con todo, combinando elementos restauradores y utópicos, la idea mesiánica siempre tiende hacia el futuro. G. Páttaro explica que "para la tradición bíblica el sentido de todo lo que sucede reside fundamentalmente en el futuro, de tal manera que el centro de gravedad de toda la línea del tiempo está situado completamente hacia delante. Por el contrario, respetando esta visión del tiempo, el Nuevo Testamento presenta una interpretación diferente, ya que sitúa el punto central del que depende la significación del desarrollo del tiempo, no en el límite situado entre el tiempo presente y el tiempo futuro, allí donde uno se transforma en otro, sino en el interior mismo del tiempo presente. La conciencia cristiana reconoce, en efecto, que el paso del antiguo al nuevo 'eón' se produce en el tiempo en que viven los hombres y se identifica con la era mesiánica, que se cumple con la llegada de Cristo" (17).

Lacunza pretendió explícitamente un sistema capaz de franquear esa línea divisoria que separaba las experiencias judía y cristianas relativas al tiempo. Como fiel cristiano nuestro autor reconoce, evidentemente, que Cristo es el centro del proceso histórico universal, reitera la creencia cristiana en las dos venidas y subraya que ante el incumplimiento de ciertas promesas fundamentales es necesario aguardar de la segunda venida el pleno cumplimiento. Para Lacunza, la era mesiánica tendrá lugar efectivo en el futuro.

En opinión de Lacunza, "el tiempo del Mesías, el tiempo de Cristo (según todas las Escrituras antiguas, y nuevas, y según todos los principios fundamentales del Cristianismo) no es uno solo, sino dos tiempos infinitamente diversos entre sí. Uno que ya pasó, y que persevera hasta ahora en sus efectos, ciertamente grandes, y admirables; otro que todavía no ha llegado, pero que se cree, y espera con fe y esperanza divina: el cual tiempo segundo parece todavía más grande y más admirable, según las mismas Escrituras, que se enderezan a él manifiestamente, y en él se terminan. Este es el tiempo, de que tanto hablan los profetas cuando dicen: 'en aquel

(16) Scholem, o. c., p. 26.

(17) Páttaro, o. c., p. 207. 
día', ... 'en los últimos días',... 'en el siglo venturo', etc. Este es el tiempo, de que tanto hablan en sus epístolas San Pedro y San Pablo diciendo frecuentísimamente: 'en el día de nuestro Señor Jesucristo', en el día de la venida del Señor... de su reino, etc. Y este es el tiempo mismo de que tanto habló 'en parábolas' ... el mismo Mesías, como se puede ver en los evangelios" (18).

Son indudables los efectos del primer tiempo. En este primer tiempo, el Mesías, Jesucristo, ha desarrollado un servicio pacífico, amistoso, modesto, en el que ha procurado "hacer todo el bien posible a cualquiera que quiera recibirlo; sufriendo al mismo tiempo, con profundo silencio, y con infinita paciencia, descortesías, ingratitudes, injurias y persecuciones" (19). Diversas profecías hablaban precisamente del Mesías como de un Maestro, ejemplo de toda justicia, como de un hombre manso, pacífico y humilde, injustamente perseguido; hablaban de sus llagas, de su desnudez en la cruz, de su afrenta, confusión y dolor; hablaban, en fin, de su muerte y resurrección de su ascensión a los cielos, de su descanso y gloria a la diestra de Dios hasta otro tiempo (20). Jesús, en suma, como sacerdote y doctor convidó a los hombres a hacerse dignos del reino futuro. Anunció el "evangelio del reino", exhortando a vivir con perseverancia la fe y la justicia en este mundo actual para así ser dignos de participar en el reino porvenir.

"Mas -señala Lacunza- con todo eso las profecías no se han verificado plenamente, pues no solo hablan del primer tiempo del Mesías, sino también, y mucho más del segundo tiempo, que todavía se espera" (21). Ahora bien, este segundo tiempo no es como pensaban algunos (muchos) doctores cristianos, un tiempo que solo se dejará ver al fin del mundo, "esto es, cuando todo el linaje humano, y todos sus individuos, sin faltar uno solo, estemos no solo muertos, sino resucitados, y congregados en el Valle (tan grande como pequeño) de Josafat, para el juicio universal. Porque ese segundo tiempo del Mesías - piensan esos doctores- deberá ser únicamente para destruirlo todo y acabar con todo: para arrojar a los malos al infierno, y llevar al cielo a los buenos, etc.” (22). Según nuestro autor no se trata de eso, para él las Escrituras ofrecen una idea infinitamente diversa. Ciertamente no se trata, como ya se ha visto, de un fin aniquilador, sino de un fin de este siglo, de una transformación del mundo para mejor y se trata del inicio del reino de felicidad, justicia y paz tan esperado por los siglos (23).

En fin, para nuestro teólogo, tanto el sistema cristiano habitual como el de los doctores judíos representan "dos mitades" que unidas pueden llegar a conformar un único y correcto sistema. Lacunza piensa que la síntesis, para él necesaria, se lograría si, por un lado, los hermanos judíos "se hicieran cargo de las circunstancias que habían de acompañar la primera venida del Mesías, según las Escrituras, y por consiguiente la creyesen", y si, por otro, los doctores cristianos "que creen la primera, y esperan la segunda, hiciesen reflexión sobre tantas profecías, que hablan mani-

(18) Lacunza, o. c., III, pp. 348-349.

(19) Ibíd., I, p. 288.

(20) Cf., Ibíd., III, pp. 351-352.

(21) Ibíd., III, p. 349.

(22) Ibíd., III, p. 353.

(23) Cf. Ibíd., III, pp. 394, 414-415. 
fiestamente de esta y no de la primera y que, por tanto, entonces, solo tendrán su entero cumplimiento" (24).

\section{TENSIÓN TEMPORAL Y ACCIÓN EN EL SISTEMA DE LACUNZA}

Si bien es cierto que el fundamento de la esperanza está en último término en Dios y la venida del Mesías es condición de posibilidad de toda realización auténtica, esto no implica que el hombre pueda esperar pasivamente el reino futuro. El anuncio de la promesa del reino va unido a una exigencia de acción. Lacunza no niega la acción ni la libertad de obrar, lo que niega es que esta acción pueda producir el reino de Dios. Tampoco cabe en la mente del autor la idea actual, más o menos habitual -aunque nunca suficientemente esclarecida- que sostiene la posibilidad de una anticipación del reino en el aquí y ahora de esta historia. Lacunza desconoce toda perspectiva de anticipación, sea esta institucional o ética, económica o política del reino. Está convencido de que el reino solo lo puede traer el Mesías. Mira la historia actual con el realismo que le permiten los evangelios: la historia humana no puede dejar de estar sometida a una inevitable contradicción señalada como una agonía de "trigo y cizaña". La historia es ambigua, y lo será siempre mientras dure el siglo presente (25)

Con todo, permanece la exigencia de acción. Quienes deseen participar del reino futuro y, más aún, de la vida eterna, tienen que vivir la práctica de la justicia y la fe que obra con amor. Nadie puede tener certeza de su salvación futura, nadie está en posesión de la herencia del reino; de ahí la necesidad de vivir en constante vigilancia y perseverar fielmente hasta los días finales. En este sentido, se puede afirmar, en el sistema de Lacunza, que la espera del reino es activa; y que la práctica del indisoluble binomio de fe y justicia no es un "hacer" el reino sino esperarlo activamente en permanente vigilancia de acuerdo a los valores del evangelio (26).

Toda acción humana está condicionada por una determinada experiencia existencial del tiempo. Cada ser humano, consciente o inconscientemente, actúa con un peculiar talante temporal. Todo proyecto, grande o pequeño, personal o social, micro o macro, está mediatizado por un tiempo y un espacio. El requerimiento de acción que surge del planteo mesiánico-milenarista de Lacunza no escapa a esa experiencia general de la cultura humana. La acción que se desprende de su sistema está de hecho temporalmente configurada. Desentrañar esa experiencia es lo que pretendemos en breve ahora.

El llamado a la vigilancia constante produce un particular enfrentamiento con el tiempo. Este enfrentamiento se caracteriza por una tensa expectativa, esto es, de algún modo ocupamos el tiempo mientras se produce la oportunidad ansiada y ocurre el suceso previsto, objeto de nuestra expectación. La vigilancia, por su parte, nos convoca a estar siempre de pie, esperando el momento propicio. La promesa del futuro no constituye una razón para postergar la experiencia de la fe ni la acción a

(24) Ibíd., III, p. 74.

(25) Cf., Ibíd., IV, pp. 263-267.

(26) Cf. Ibíd., I, p. 337; II, p. 494; III, p. 146; IV, pp. 143, 431. 
favor de la justicia. La ignorancia cronológica con respecto al acontecimiento central, esto es, el desconocimiento del 'cuándo', va unido al carácter inminente del mismo suceso. 'Inminente', es decir, que está próximo a suceder. Todo esto se traduce finalmente en una experiencia de actualidad absoluta (27). El mundo nuevo puede irrumpir en cualquier momento del presente. Es lo que ocurre con Lacunza: en toda su obra podemos percibir el carácter inminente del reino y junto con ello su explícita negación a calcular fechas. En un pasaje sugiere que podrían pasar siglos antes que se desaten los acontecimientos finales, por otra parte, el final de este siglo, que ya está llegando a un colmo del mal, y la llegada del reino futuro son inminentes: "así como ninguno sabe cuándo bajará la piedra (Cristo), ni Dios lo ha revelado, ni lo revelará jamás; así ninguno puede saber quiénes serán entonces las cabezas del reino (político), ni las novedades que en él habrá en los siglos venideros. Por eso, el mismo Señor nos exhorta con tanta frecuencia en los evangelios a la vigilancia en todo tiempo, porque no sabemos cuándo vendrá" (28). En la situación en que se encuentra el siglo presente, de acuerdo al planteo lacunziano, cualquier momento puede ser la abertura por donde ingrese el Mesías y llegue el mundo nuevo. El reino viene de un modo inesperado.

En consecuencia, la idea moderna de progreso, tal como se elabora a partir del siglo XIX, es ajena a la mentalidad de Lacunza y, por lo mismo, no podía acudir a ella para explicar la relación humana con la esperanza del reino. La idea de que la historia marcha irreversiblemente hacia días mejores, hacia la consumación de un ideal concebido como objeto de un proyecto racionalmente concertado, no forma parte del universo conceptual lacunziano. Para el autor de La Venida del Mesías en gloria y majestad, el reino es futuro, ciertamente, pero su adviento no es previsible ni es resultado de una planificación determinada por nuestro esfuerzo. La anticipación, ya lo hemos dicho, tampoco es posible. El reino futuro del Mesías se hará visible libre y soberamente.

\section{PARUSÍA Y TIEMPO EN EL DEBATE CONTEMPORÁNEO}

El anuncio de la venida de Jesucristo se contiene en todas las manifestaciones de la fe de la Iglesia, a saber, en el testimonio de los Padres, en la Liturgia, en los símbolos de fe. Con todo, es innegable "que el pensamiento de la parusía ha sufrido una progresiva neutralización, de la patrística a la teología medieval, y de esta hasta nuestros días" (29). El historiador chileno Mario Góngora, atento lector e investigador de la obra de Lacunza y sus repercusiones, afirma que "se conoce bien el proceso histórico por el cual las primeras esperanzas escatológicas de la Parusía y del Reino empalidecieron progresivamente, no sin crisis y violentas erupciones.

(27) Cf. K. Mannheim, Ideologia e utopia, Guanabara, Río de Janeiro, 1986, pp. 235-243.

(28) Lacunza, o. c., I, p. 298.

(29) "Bastaría para probarlo - añade Ruiz de la Peña- el hecho de que, desde la Edad Media hasta el Vaticano II, solo dos veces aparece en documentos del magisterio: en el cuarto concilio de Letrán (DS 801=D 429) y en la profesión de fe del emperador Miguel Paleólogo (DS 852=D 462); en ambos casos se trata de simples alusiones rutinarias" (J. L. Ruiz de la Peña, La pascua de la creación, BAC, Madrid, 1996, pp. 130-131). 
Hacia los siglos XIII y XIV se constituyó una situación en que la Iglesia jerárquica y sacramental 'es ya' el Reino, simbólica y jurídicamente; su perfección real se daría para cada hombre en el Más Allá, en la Iglesia Triunfante; el Juicio Final no era sino la sanción solemne del encuentro ya consumado para cada alma. La efervescencia de una escatología realizada en el futuro histórico terrestre solo se mantiene en el mundo subterráneo de las sectas o de los pensadores solitarios de tipo Joaquinita o Milenarista" (30). Entre estos pensadores solitarios habría que situar, sin duda, a Lacunza, quien viviendo las difíciles circunstancias de las últimas décadas del siglo XVIII supo rescatar y profundizar, desde su perspectiva particular, es decir, mesiánico-milenarista, la fe en la Segunda venida de Jesucristo.

Hoy ya no se discute que la idea-esperanza de la parusía o venida de Jesucristo es un tema de indudable importancia en la experiencia creyente neotestamentaria. Lo que sí cabe recordar es que su reestudio y renovación se extiende desde fines del siglo XIX hasta la actualidad. Diversos teólogos y exegetas desde J. Weiss, A. Schweitzer y K. Barth hasta J. Moltmann, por el lado protestante, Nicolai Berdiaev, por la teología ortodoxa rusa, y desde Teilhard de Chardin hasta J. L. Ruiz de la Peña, pasando por K. Rahner, E. Schillebeeckx, H. U. von Balthasar y J. B. Metz, en el ámbito católico, han recuperado la centralidad de la escatología. Conocido es el crucial aporte del Concilio Vaticano II (31) para dar el sitio correspondiente a la perspectiva escatológica y particularmente a la fe en la parusía (32).

(30) M. Góngora, Civilización de masas y esperanza, Vivaria, Santiago de Chile, 1987, p. 128. Id., La obra de Lacunza en la lucha contra el "Espíritu del Siglo" en Europa 1770-1830, Revista Historia 15 (1980), pp. 7-65. A. F. Vaucher, Lacunza, un heraldo de la Segunda Venida de Cristo, Ed. Interamericanas, California-U.S.A., 1970.

(31) Cf. J. Alfaro, Reflexiones sobre la escatología del Vaticano II, en R. Latourelle (ed.), Vaticano II. Balance y perspectivas, Salamanca, 1989, pp. 789-797; C. Pozo, La doctrina escatológica del Concilio Vaticano II, en Id., Teología del más allá, Madrid, 1968, pp. 9-47. J. R. Flecha, Ultimas teologías sobre Ultimidades, Salmanticensis, 25 (1978), pp. 99-105; J. Noemi, Sobre el enfoque escatológico del Vaticano II y su vigencia en la teología católica, Teología y Vida, 29 (1988), pp. 49-59; R. Michel, Le retour de l'Eschatologie dans la Théologie contemporaine, Revue de Sciences Religieuses, 58 (1984), pp. 180-195; W. Pannenberg, Constructive and critical funtions of Christian Eschatologie, Harvard Theological Rev., 77 (1984), pp. 119-139; A. Tornos, Boletín. Publicaciones sobre escatología 1979-1989, Miscelánea Comillas, 47 (1989), pp. 301-317; Santiago del Cura Elena, Escatología contemporánea: la reencarnación como tema ineludible, en: VV. AA., Veinticinco años de quehacer teológico, Ed. Aldecoa, Burgos, 1994; T. Zolezzi, La enseñanza escatológica del Vaticano II, 30 años después, Teología y Vida, 38 (1997), pp. 139149. T. Rast, Escatología, en H. Vorgrimler y R. Vander Gucht, La teología en el siglo XX, Tomo III, BAC, Madrid, 1974, pp. 245-263.

(32) A propósito de esto, en otro lugar hemos observado críticamente que "como término consumador de la historia, la parusía supera toda representación y se resiste a toda concreción imaginativa. El tiempo y la historia acaban con la muerte y la resurrección y, por lo mismo, la diferenciación periódica de tiempos y espacios posteriores no solo sobrepasan toda lógica histórica sino que el mero intento de determinar, de acuerdo a nuestras categorías, modos concretos de una vida postparusía, desbordan ampliamente las posibilidades del pensamiento representativo. En fin, dejando por ahora de lado diversos aspectos ya criticados en otro lugar (Cf. F. Parra, El Reino que ha de venir. Historia y esperanza en la obra de Manuel Lacunza, Anales de la Facultad de Teología, PUCCh, Vol. XLIV, c. 2, Santiago de Chile, 1993, pp. 153-211), lo problemático es que Lacunza no evita representar lo irrepresentable, objetiva aquello que quizá escapa a toda objetivación, exponiéndose con ello al riesgo de inconsistencia de su sistema. En efecto, la parusía es límite y acabamiento del devenir histórico y por ello todavía concierne a la historia. Pero, al ser plenificación de la misma historia, en cuanto manifestación de la novedad que trae el Resucitado, supera la lógica histórica. Baste recordar aquí las palabras del Concilio Vaticano II: "Ignoramos 
Parece importante reseñar brevemente un capítulo notable del debate escatológico que ha marcado la reflexión del último siglo y que dice relación, precisamente, con la interpretación de la parusía. Tanto las interpretaciones de Ch. H. Dodd (33) como las de R. Bultmann (34) y del "primer" G. Greshake acaban negando la realidad objetiva de la parusía (35). Al negar el acontecimiento de la parusía estas visiones conducen a una radical privatización y destemporalización de lo escatológico. El interés exclusivo por el sentido en desmedro del evento implica una fuga del tiempo, una deshistorización. Como señala acertadamente Ch. Duquoc tomando posición en esta polémica: la postura que individualiza el plazo y lo minimiza, finalmente, "suprime la historia y tiende hacia una gnosis o un docetismo" (36). Negar la parusía y junto con ella la expectativa cercana que conlleva, no solo deja en la penumbra la tensión escatológica inherente al pensamiento de Jesucristo, sino

el tiempo en que se hará la consumación de la tierra y de la humanidad. Tampoco conocemos de qué manera se transformará el universo..." (GS, 39)...(En el planteo de Lacunza) siempre se trata de una transformación de la materia de mal en bien, o de bien en mejor. Se excluye, clara y expresamente, la idea de un "fin del mundo" como aniquilación del mismo. Este planteo fundamental se aproxima a la visión escatológica del Concilio Vaticano II que subraya no solo la diferencia sino también la continuidad entre este mundo y la bienaventuranza eterna: "la figura de este mundo afeada por el pecado, pasa, pero Dios nos enseña que nos prepara una nueva morada y una nueva tierra donde habita la justicia, y cuya bienaventuranza es capaz de saciar todos los anhelos de paz que surgen del corazón humano. Entonces, vencida la muerte, los hijos de Dios resucitarán en Cristo... y permaneciendo la caridad y sus obras, se verán libres de la servidumbre de la vanidad todas las criaturas que Dios creó pensando en el hombre" (GS, 39) (Cf. F. Parra., Crítica y actualidad de Lacunza, Artes y Letras, El Mercurio, 17 de junio de 2001, E-13)

(33) Para Dodd se trata de un encuentro de la persona individual con Dios al término de su existencia. De acuerdo a su análisis nada se opone a considerar la historia como un proceso indefinido y abierto: "un final absoluto de la historia, tanto si se le concibe próxima como tardíamente futuro, no es más que una ficción diseñada para expresar la realidad de la teología dentro de la historia": (Ch. H. Dodd, La predicación apostólica y sus desarrollos, Madrid, 1974, p. 98).

(34) En la línea de Bultmann la parusía tiene lugar cada día, en el hoy de la decisión estimulada por la crisis permanente que produce la palabra de Dios en el sujeto. Cf. J. L. Ruiz de la Peña, La otra dimensión. Escatología cristiana, Sal Terrae, Santander, 1986, pp. 30-33; 115-119.

(35) En su tesis doctoral publicada en 1969 (Die Auferstehung der Toten), Greshake distingue entre consumación (Vollendung) y fin (Ende) de la historia del mundo; la consumación concierne a la libertad humana (una presentación detallada de esta tesis se puede ver en Ruiz de la Peña, La otra dimensión..., pp. 167-171). Ruiz de la Peña critica oportunamente esta posición porque considera que también llega a una privatización radical del último día y niega la realidad objetiva del eschaton como fin de la historia humana. En su opinión, Greshake no ha interpretado suficientemente textos como 1 Co 15, 20-28 en que se habla claramente de un telos de la historia y $\mathrm{Rm} 8$, 19-24, Ef 1 y Col 1, en los cuales se refiere la dimensión cósmica de la salvación. "La renuncia a un término real de la historia acabaría con la tensión 'ya-todavía no'; ese 'todavía no', singularización de la actitud escatológica, sería sustituido por un incesante 'cada vez más'. Pero 'no hay redención a través de una historia progresiva: la redención es también redención de (von) la historia'. Así pues, la existencia de un acontecimiento final, de 'un último día', no puede ser revocada como elemento mítico-apocalíptico sin comprometer toda la escatología. No habrá tan solo consumación; habrá además término. O mejor: porque habrá una consumación habrá un término consumador" (Ruiz de la Peña, La otra dimensión..., p. 171). Rectificando su hipótesis inicial, Greshake ha optado finalmente por no negar la parusía como evento objetivo y fin de la historia. Pero continúa afirmando una 'resurrección en la muerte' como un intento de superar el dualismo que subyace en la concepción del alma separada y del estado intermedio. Cf. J. B. Libanio, Recensión a G. Greshake y J. Kremer, Resurrectio Mortuorum: Zum theologischen Verständnis der leiblichen Auferstehung, Darmstadt, Wissenschaftliche Buchgesellschaft, 1986, en Perspectiva Teológica, 57 (1990), pp. 256-259.

(36) Ch. Duquoc, Cristología II. Ensayo dogmático, Sígueme, Salamanca, 1972, p. 403; cf. pp. 375 424. 
que de paso la privan de su dimensión colectiva reiterando una nueva fuga de la historia. Es más, en opinión de Metz "la versión interpretativa que la teología ha hecho de la 'expectativa cercana' como 'expectativa permanente'... es un fraude semántico contra la estructura temporal básica del cristianismo, cuyo núcleo no es intemporal, sino precisamente temporal; esta interpretación confirma indirectamente hasta qué punto la teología misma ha sucumbido ya a la presión anónima de una conciencia evolucionista del tiempo o, más exactamente, a una destrucción evolucionista del tiempo" (37).

Sintetizando su investigación cristológica (38), E. Schillebeeckx, afirma que "la cristología de la parusía es la madre de todo cristianismo: Jesús es 'el que vendrá'. Con otras palabras: la madre de todo cristianismo no es la apocalíptica como tal, sino la convicción de fe de que a pesar de las apariencias en contra, el reino de Dios se acerca. Por eso, la petición fundamental del cristianismo es 'Venga a nosotros tu reino'... La cristología de la parusía del profeta escatológico se desarrolla enteramente bajo el signo del reino de Dios, anunciado por Jesús, y de la función mediadora de Jesús en esta venida" (39). La llegada futura del reino o su plenitud, es decir, la parusía, implica un límite al tiempo, y por ello, constituye su condición de posibilidad (40).

Ya en los comienzos de la segunda década del siglo pasado, recogiendo la tradición del mesianismo ruso, N. Berdiaev insistía en que sin la idea de una meta no es posible entender lo que es la historia, no se puede concebir el movimiento histórico mismo, que en cuanto tal solo posee un sentido en la medida en que se encamina a un fin consumador (41).

Más recientemente, Ruiz de la Peña, en su obra póstuma, ha observado que si se opta por la tesis de una historia interminable o de un processus in infinitum, "se secuestra a la realidad en un estatuto de inacabamiento crónico, en un incurable déficit ontológico: nada llega a ninguna parte, todo queda a medio hacer. Por otra parte, es un hecho que cuantas veces se ha propuesto la idea de una historia indefinidamente abierta, se la ha emplazado en una comprensión cíclica del tiempo, pues solo el círculo puede dar razón de la perennidad del proceso: en una órbita circular no hay pérdida de energía, el proceso se realimenta a sí mismo permanente e interminablemente... Sin un término que sostenga la tensión a lo largo del entero proceso, polarizándolo e imantándolo hacia sí, la historia que se pretendía rectilínea... se encurva y acaba por cerrarse sobre sí misma" (42).

(37) J. B. Metz, La fe en la historia y la sociedad, Cristiandad, Madrid, 1979, p. 182. En este contexto, se entiende la reflexión del mismo Metz: "fundamentalmente no se trata del problema (supuestamente 'cristiano') de cuánta salvación poseemos 'ya' y cuánta 'todavía no'..., sino de la pregunta: ¿cuánto tiempo tenemos (aún)? Esta es la pregunta escatológica por el tiempo, la cual corresponde a la esencia no evolucionista del tiempo" (ibíd, p.187). Cf.: G. Páttaro, o. c.

(38) E. Schillebeeckx, Jesús. La historia de un Viviente, Cristiandad, Madrid, 1981.

(39) E. Schillebeeckx, En torno al problema de Jesús. Claves de una cristología, Cristiandad, Madrid, 1983, p. 100; Cf. id., Jesús, la historia de un Viviente..., pp. 375-379.

(40) Para J. B. Metz, “'la eternidad' como lo contrario del tiempo humano, no es Dios, sino... naturaleza o, más exactamente, Deus sive natura. Dios no es, según la Biblia, lo otro que el tiempo, sino su fin, su límite, su ruptura y, justamente por ello, su posibilidad” (J. B. Metz, o. c., p. 183).

(41) N. Berdiaev, El sentido de la historia, Ed. Encuentro, Madrid, 1979, p. 37 ss.; Id., Essai de Métaphysique Eschatologique, Aubier, Paris, 1946, pp. 223-230.

(42) J. L. Ruiz de la Peña, La pascua de la creación..., p. 17. 
Con palabras de N. Berdiaev, quien en vida mostró interés y aprecio por la obra de Lacunza: "la historia solo puede tener un sentido positivo si posee un final... Si la historia fuese un proceso sin final, una infinidad perversa, carecería de sentido; la tragedia del tiempo no tendría salida alguna y el objetivo de la historia sería irrealizable, al no poder ser realizado en el ámbito del tiempo histórico. El destino del hombre, que está en la base de la historia, presupone una finalidad metahistórica... una realización metahistórica del destino de la historia, realización que se sitúa en una dimensión diferente, eterna...; al final de la historia, 'este mundo' enclaustrado en sí mismo, esta realidad terrestre dejará de existir. El eón en que se sitúa nuestro mundo va envejeciendo poco a poco; al igual que un fruto cuya cáscara revienta cuando está maduro, la corteza que separa a nuestra realidad terrestre del otro mundo estalla y desaparece... Se rompen las ataduras del tiempo, ... e irrumpen en él las energías de otros niveles de realidad; la historia de nuestro mundo termina y, a través de este final, adquiere un sentido" (43).

También esta experiencia del tiempo nutre la acción. Esperar es también operar, la esperanza no es ajena a la acción vigilante y confiada. "El esperante cristiano ha de ser operante en la dirección de lo que espera. Esperar la parusía es creer que Cristo ha vencido la injusticia, el dolor, el pecado, la muerte; exige por tanto no resignarse pasivamente ante la persistente emergencia de estos fenómenos", añade Ruiz de la Peña (44). También aquí es preciso mirar a Jesús y observar que su visión del reino de Dios "se fue configurando en y por una praxis fragmentaria, histórica $-\mathrm{y}$, por tanto, limitada y finita-, mientras 'iba de un sitio a otro haciendo el bien' [...] Jesús, pues, no vivió de una visión utópica y lejana ni de la convicción de que todas las cosas habían alcanzado 'idealmente' su consumación en Dios, sino que vio en su praxis concreta de hacer el bien un anticipo práctico de una salvación todavía no consumada" (45).

El acontecimiento Jesucristo es el centro del devenir temporal, su muerte y resurrección, y ciertamente su parusía, constituyen la clave para entender y comprender la experiencia que el cristiano hace del tiempo. Orientado hacia la Segunda venida, el tiempo queda cualificado por una ambigüedad, por una tensión, que la teología contemporánea describe como una tensión entre un ya realizado y lo que todavía permanece pendiente (46). La postura de F. J. Nocke intenta un consenso al sostener que la fe en la parusía afirma dos extremos: de cara al futuro, "vendrá el día en que Cristo reine"; de cara al presente, "cada día, podemos y debemos contar con el encuentro con Cristo: en la exigencia concreta del amor al prójimo [...]. Los dos aspectos forman una unidad. De esta manera, la esperanza en la parusía no

(43) Berdiaev, El Sentido de la historia..., pp. 180-181.

(44) Ruiz de la Peña, La pascua de la creación..., p. 141.

(45) E. Schillebeeckx, Cristo y los cristianos, Cristiandad, Madrid, 1982, p. 776. Es más "si se prescinde de esta historia religiosa de Jesucristo, nos encontramos, como mucho, frente a una utopía liberadora, que sugiere quizá algunas posibilidades de vida y salvación para hombres alejados del horizonte de nuestra historia, pero que excluye de esta prehistoria al resto de la humanidad, en beneficio de una utopía futura. La salvación definitiva trasciende nuestra experiencia actual... pero si ese anuncio de salvación puede y debe ser considerado como válido, es porque tiene su fundamento en un contexto experiencial presente: Jesús, los que le siguen 'en este mundo' y todos los que actúan como él” (Schillebeeckx, En torno al problema de Jesús..., p. 170). Cf., Páttaro, o. c. pp. 201-211. 
queda despedazada en los cumplimientos fragmentarios de este tiempo; pero tampoco se desplaza a una lejanía indefinida; más bien convierte el presente en comienzo de la consumación esperada" (47).

A. Gesché nos ha recordado recientemente que el cristianismo ha superado definitivamente visiones pesimistas respecto al mundo y a la historia, particularmente el paradigma griego, estableciendo tres aportes revolucionarios en la concepción del tiempo. En primer lugar, "el tiempo-chronos, el tiempo de esta tierra, no es un tiempo devaluado". Asumiendo su herencia veterotestamentaria, la fe cristiana invita al ser humano a vivir su vocación en el tiempo y a "convertirlo en el lugar de una historia". En segundo lugar, "el tiempo-aiôn, el tiempo de eternidad, no está reservado solo para Dios, sino que es accesible al hombre". Finalmente, la eternidad "viene a visitar el tiempo (chronos)". Aquí interviene la noción de tiempo favorable, tiempo oportuno: kairós. "El kairós es el tiempo de la visitación del tiempo por la eternidad". Así "el tiempo de nuestra temporalidad queda atravesado por flechas de eternidad, por tiempos fuertes de Dios y por momentos de impulso del hombre hacia su destino" (48). La encarnación, la venida del reino, los signos de los tiempos, la parusía, son, precisamente estos tiempos fuertes de Dios que conducen al hombre hacia su destino. Y lo conducen a través de la misma historia. Es más, como bien señala J. Noemi, "del Dios de Jesucristo no es posible articular un discurso válido al margen de la historia" (49).

En definitiva, "lo que hace excepcional y singular la interpretación cristiana es la afirmación de que el kairós de Cristo, mientras está situado en el tiempo y, por consiguiente, integrado en él, volviéndose pasado, no quita al futuro su significación propia, de tal manera que el futuro no se reduce a una simple memoria prolongada del 'momento-acontecimiento' Cristo. (...) Aunque definitivamente llegado ya, Cristo sigue siendo siempre el que debe venir, puesto que el 'último día' del tiempo presente es el 'día del Señor', que llevará un juicio sobre aiôn outos (siglo actual) para abrir definitivamente el camino a la plenitud del aiôn mellón (siglo futuro). Existe para el cristianismo una parusía que debe cumplirse aún, de tal manera que, en el tiempo presente, están todavía en juego el pasado y el futuro, que ofrecen sus significados al tiempo que se sitúa entre el Cristo que ya ha venido y el Cristo que todavía debe venir. Así pues, en nombre de Cristo, la interpretación judaica, que subraya siempre el futuro, está superada porque Cristo se 'manifestó' pero, al mismo tiempo, se mantiene dicha interpretación, ya que 'su venida' todavía es esperanza" (50).

En la esperanza de la parusía y la resurrección la disociación de hecho existente entre pasado, presente y futuro encuentra una superación viable. Nicolai Berdiaev -profundizando el clásico análisis de San Agustín-, ha explicado suficientemente cómo estas tres dimensiones del tiempo se encuentran sometidas a una mutua devoración; el tiempo de nuestra realidad mundana es un tiempo desgarrado en pasado, presente y futuro. "El futuro devora al pasado para transformarse, a su vez en un pasado que será devorado por el subsiguiente futuro. La separación entre pasado y

(47) F. J., Nocke, Escatología, Herder, Barcelona, 1984, pp. 68-69.

(48) A. Gesché, El destino, Ed. Sígueme, Salamanca, 2001, pp. 110-112.

(49) J. Noemi, Escatología cristiana: ¿fuga o hallazgo del tiempo?, en VV. AA., La teología del tiempo, Sociedad Chilena de Teología, Ed. San Pablo, Santiago de Chile, 1998, p. 180.

(50) Páttaro, o. c., p. 208. 
futuro es... el defecto, el mal fundamental del tiempo mundano" (51). Y el presente casi no puede existir situado en un punto efímero donde el pasado ya no es y el futuro aún no adviene. El tiempo parece aguardar una cierta redención que le devuelva su integridad, que supere sus quiebres y fragmentación.

"En realidad, -como bien señala Berdiaev- la conciencia religiosa no puede soportar la idea de que algo auténticamente vivo pueda morir y desaparecer. El cristianismo es la más sublime de las religiones sobre todo porque es la religión de la resurrección, porque no acepta la muerte definitiva y la desaparición, porque busca la resurrección de todo lo que tiene existencia auténtica" (52). Solo la resurrección rescata plenamente, creemos, la historia personal, social y cósmica.

Solo una palabra para concluir. Insertos en un tiempo, como el nuestro, atomizado y con horizontes comunes debilitados, en medio de una paradójica experiencia de lo nuevo y siempre idéntico (53), donde muchas veces es dable constatar un eclipse del sentido ante la irremediable ambigüedad de diversos acontecimientos, es posible que estas voces que nos llegan de un pasado-presente nos ayuden a contemplar el tiempo con una mayor autenticidad y a descubrir con nuevos ojos que el Reino sigue llegando discretamente allí donde la acción del justo provoca un retroceso del mal siempre amenazante.

Finalmente, no puedo dejar de citar a nuestro homenajeado: hacia el final de su extensa obra, y con tono exhortativo, Lacunza nos dice: "En suma, no perdamos tiempo: la felicidad suma, completa y eterna que está prometida... a los justos, hermanos menores del Hombre Dios, conformes a la imagen de su Hijo, no podremos alcanzarla jamás, si no nos servimos de aquellas dos alas absolutamente necesarias e indispensables, que son fe y justicia. Sin estas alas, no separadas, sino unidas entre sí, y ayudándose mutuamente como buenas hermanas, no tenemos que esperar la herencia en el reino de Cristo y de Dios... ni ser coherederos de Cristo, pues se nos pide... que padezcamos con él, para que seamos también glorificados con él" (54).

\section{RESUMEN}

El artículo pretende profundizar la perspectiva del tiempo que se encuentra explícita o implícita en la obra de Lacunza. Para ello desarrolla el pensamiento lacunziano en torno a los siguientes tópicos: la relación entre tiempo, 'eones' y eternidad; la peculiar visión de los dos tiempos o venidas del Mesías; los vínculos que se establecen entre la experiencia del tiempo de una conciencia determinada por la inminencia del fin y la posible acción humana en la historia. Finalmente, sitúa los aportes de este autor milenarista del siglo XVIII en el debate contemporáneo y actual relativo a la Parusía y el tiempo. Para Lacunza, la historia constituye una profunda interacción entre la eternidad y el tiempo, el advenimiento constante de aquella en este; tanto el 'siglo presente' como el 'siglo futuro' aspiran a un tiempo íntegro, pleno, de felicidad y realización sin límites. Es decir, el tiempo está habitado por un anhelo profundo de eternidad. En la esperanza de la Parusía y la Resurrección, el drama de un tiempo siempre desgarrado en pasado, presente y futuro, encuentra una superación definitiva. La historia po-

(51) N. Berdiaev, El sentido de la historia..., p. 70

(52) Ibíd., p. 72.

(53) J. M. Mardones, ¿Adónde va la religión? Cristianismo y religiosidad en nuestro tiempo, Sal Terrae, Santander, 1996, pp. 161-169.

(54) Lacunza, o. c., IV, pp. 431-432. 
see sentido en la medida que se encamina hacia un fin consumador y plenificador. En suma, solo la Resurrección rescata y salva plena y auténticamente la historia personal, social y cósmica.

\begin{abstract}
This article examines the notion of time explicit or implicitly stated in the work by Lacunza. To do so, the author discusses Lacunza's thought regarding the following topics: the relation between time 'eons' and eternity; his peculiar view of the two comings of the Messiah; the links established between the experience of time of a particular conscience that has been typified (epitomized) by the immediacy of the end time and the possible human action in history. Finally the article sets Lacunza's contributions in the contemporaneous debate concerning the Final Things and Times. For him, history establishes a deep interaction between time and eternity and in their merging, both the 'present and future' time, aims at an unblemished and blissful time. The tragedy of an ever broken time; past, present, future, finds it definite accomplishment in the expectation of the last days and the resurrection. History makes sense as long as it approaches toward a fulfilling end, that is only the Resurrection rescues and saves fully and authentically the personal, social and cosmic history.
\end{abstract}

